\title{
Enhancement in solar cell efficiency by luminescent down-shifting layers
}

\author{
Hind A. Ahmed ${ }^{* 1}$, James Walshe ${ }^{1 \mathrm{a}}$, Manus Kennedy ${ }^{\mathrm{b}}$, Thomas Confrey ${ }^{1 \mathrm{c}}$, \\ John Doran ${ }^{1 \mathrm{~d}}$ and Sarah. J. McCormack ${ }^{2 \mathrm{e}}$ \\ ${ }^{1}$ Dublin Energy Lab, Dublin Institute of Technology, Dublin, Ireland \\ ${ }^{2}$ Trinity College Dublin, Dublin, Ireland
}

(Received August 13, 2013, Revised October 14, 2013, Accepted October 15, 2013)

\begin{abstract}
In this paper, core-shell semiconductor quantum dots (QDs) CdSeS/ZnS with emission at $490 \mathrm{~nm}$ and $450 \mathrm{~nm}$ were investigated for their use in luminescent down-shifting (LDS) layers. Luminescent quantum yield (LQY) of the QDs measurements in solution proposed that they were suitable candidates for inclusion in LDS layers. QDs were encapsulated in poly(methyl,methacrylate) (PMMA) polymer matrix and films were fabricated of $134 \pm$ 0.05 microns. Selections of organic dyes from BASF Lumogen F range were also investigated for their use as LDS layers; Violet 570 and Yellow 083. The addition of LDS layers containing Violet 570 dye demonstrated a unity LQY when encapsulated within a PMMA matrix. APV device of an LDS layer of Lumogen Violet 570 deposited on top of a crystalline silicon cell was fabricated where it was demonstrated to increase the efficiency of the cell by $34.5 \%$ relative.
\end{abstract}

Keywords: spectral losses; solar cell efficiency; down-shifting; luminescent materials; quantum dots; organic dyes

\section{Introduction}

The poor spectral response of Si PV devices in the spectral region below $500 \mathrm{~nm}$ is one of the main limiting factors of Si cell efficiency. Low energy photons are not absorbed by the solar cell, while high energy photons are not used efficiently and energy is lost via thermalization. Luminescent Down-Shifting (LDS) is an optical approach to increase a solar cell's spectral response by using luminescent materials to convert high energy photons to lower energy before the interaction with the solar cells occurs (Hovel et al. 1979, Cheng et al. 2001, Strumpel et al. 2007, Klampaftis et al. 2009, McIntosh et al. 2009, van der Ende et al. 2009, Le Donne et al. 2011, Rothemund et al. 2011, Klampaftis et al. 2012). The downshifted photons have wavelengths which may better match the photosensitivity spectral response of the solar cell as illustrated in Fig. 1.

* Corresponding author, PhD. Student, E-mail: hind.ahmed@mydit.ie

${ }^{a}$ B.Sc. Student, E-mail: c10392053@mydit.ie

${ }^{\mathrm{b}}$ PhD., E-mail: manus.kennedy@dit.ie

${ }^{c}$ PhD., E-mail: thomas.confrey@dit.ie,

${ }^{\mathrm{d}}$ PhD., E-mail: john.doran@dit.ie

e Associated Professor, E-mail: mccorms1@tcd.ie 


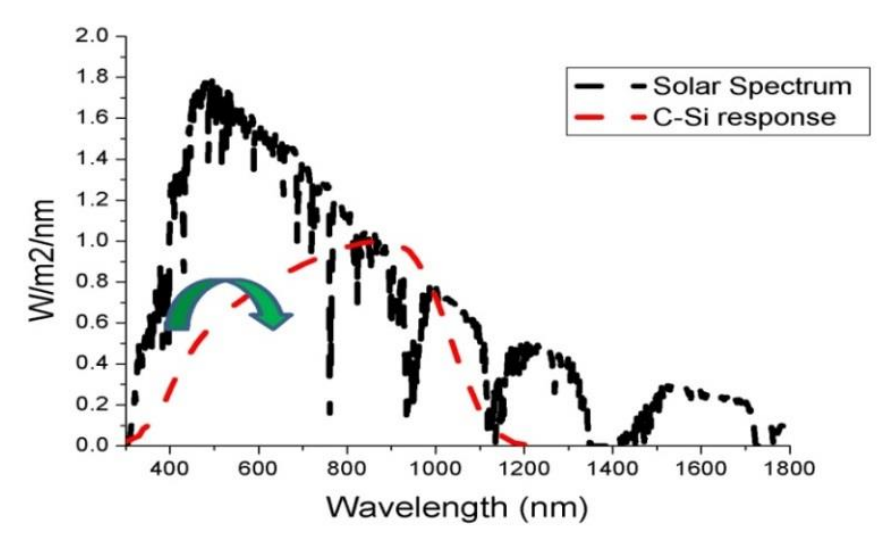

Fig. 1 Luminescent down-shifting process to increase solar cell active range and efficiency. High energy photons are re-radiated at a longer wavelength, better matching the photosensitivity spectral response of the c-Si solar cell

As a result of the luminescent process more electron-hole pairs can be created in the solar cell for a given number of incident photons and higher short-circuit current (Isc) is generated (McIntosh et al. 2009, Le Donne et al. 2011, Rothemund et al. 2011, Klampaftis et al. 2012).

LDS layer is positioned on top of a PV cell illustrated in Fig. 2. Incident solar radiation represented by ray 1 will be absorbed and re-emitted at longer wavelength. The majority of the emitted radiation will be directly absorbed (ray 2) or following internal reflection at air/LDS interface (ray 3) and transmitted to the PV cell. Light could be re-absorbed and re-emitted again by another luminescent species as in rays 4, 5 respectively. Part of the luminescence will be emitted away from the PV cell through the top or the side of the LDS layer as represented by rays 6 and 7 (the escape cone losses). Light could also be transmitted directly to the cell if is not absorbed by the luminescent species (ray 8) (Klampaftis et al. 2009).

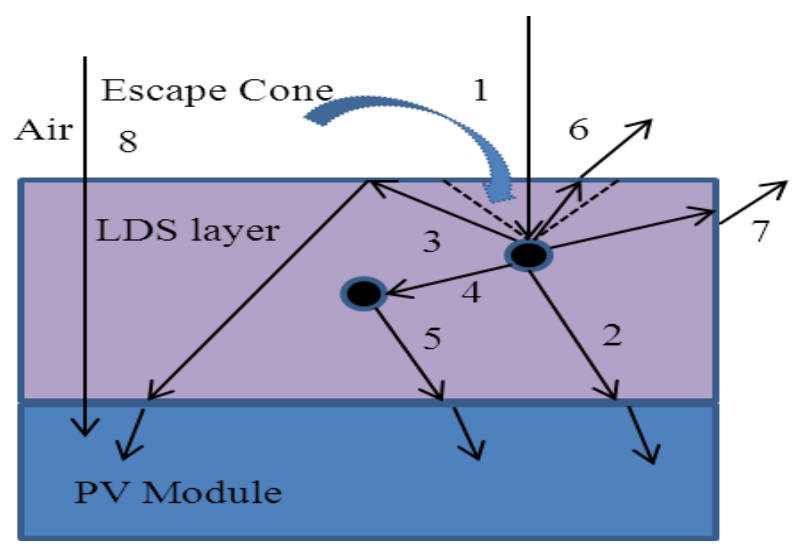

Fig. 2 Schematic diagram of PV modules with LDS layer on top (Klampaftis et al. 2009) 


\section{Experimental}

Two types of QDs with an emission peak at $450 \mathrm{~nm}$ and $490 \mathrm{~nm}$ were investigated in this study. The QDs were purchased from Cytodiagnostics in solution $(5 \mathrm{mg} / \mathrm{ml}$ in toluene solvent). They were Trilite nanocrystals (approximately $6 \mathrm{~nm}$ in size) with a $\mathrm{CdS}_{\mathrm{x}} \mathrm{Se}_{1-\mathrm{x}}$ core encased in an inner shell of CdS and outer shell of ZnS. The absorption and emission spectra of the QDs are shown in Fig. 3. Absorption and emission spectra were measured using UV/VIS spectrometer (Perkin Elmer Lamda 900) and Luminescence spectrometer (Perkin Elmer Lamda LS55B).

The Naphtalimide based Lumogen F Violet 570 and Perylene based Lumogen F Yellow organic dyes from [BASF, Germany] were also investigated in this study, their absorption and emission is shown in Fig. 4.

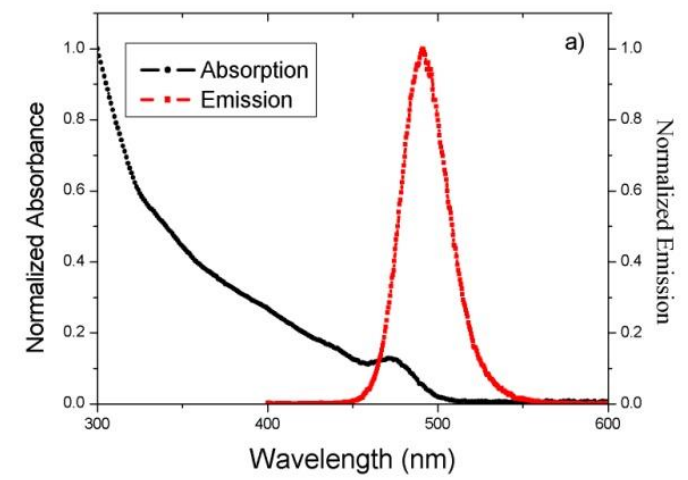

(a) QDs-490

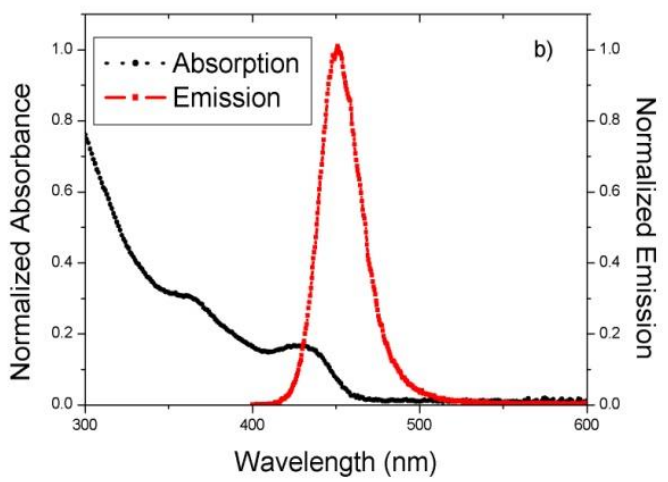

(b) QDs-450

Fig. 3 Normalized absorption (circles) and emission (squares) spectra of CdSeS/ZnS in toluene $(0.3 \mathrm{mg} / \mathrm{ml})$

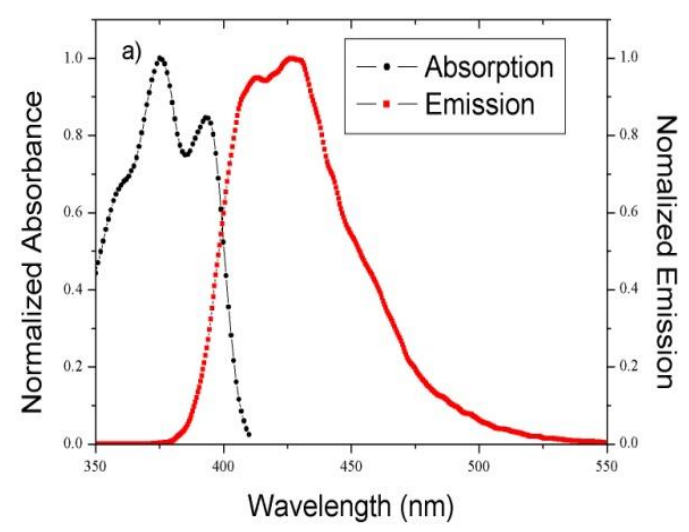

(a) Violet 570 dye

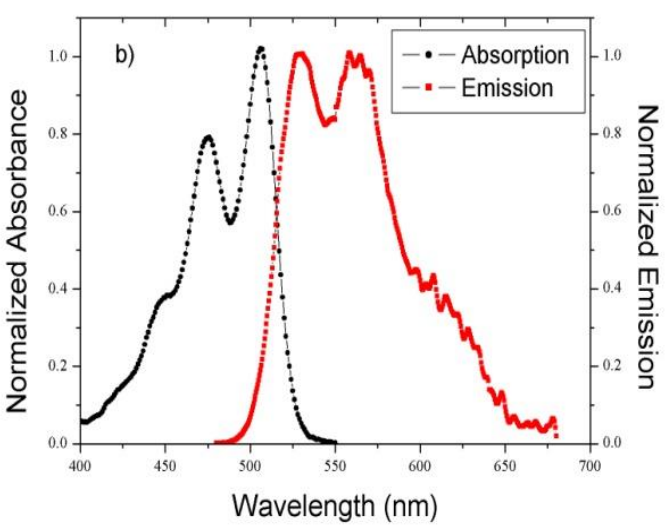

(b) Yellow 083 dye

Fig. 4 Normalized absorption (circles) and emission (squares) spectra of organic dyes in toluene $(0.1 \mathrm{mg} / \mathrm{ml})$ 
It is observed from the absorption and emission measurements that the QDs-490 and QDs-450 downshifts photons from $300 \mathrm{~nm}$ (Absorption peak) to $490 \mathrm{~nm}$ (Emission peak) and from $300 \mathrm{~nm}$ to $450 \mathrm{~nm}$, respectively. The Violet 570 downshifts photons from $378 \mathrm{~nm}$ to $413 \mathrm{~nm}$ while the Yellow 083 downshifts photons from $478 \mathrm{~nm}$ to $525 \mathrm{~nm}$.

Absorption and emission measurements of QDs and Violet dye showed they have suitable spectral properties for transfer photons from ultra-violet/blue range to visible range. The Yellow dye has strong absorption across a wide range of the visible spectrum which limits its efficiency as LDS layer. It is important to determine their luminescent quantum yield which is the ratio of photons emitted through luminescence to photons absorbed (Lakowicz 2006). Two techniques considered to determine the LQY are the 'comparative method' and the 'integrating sphere method' discussed in sections 2.1 and 2.2.

\subsection{Comparative method technique}

The comparative method ${ }^{\mathrm{f}}$ of (Williams et al. 1983) involves the use of a standard fluorescent dye to compare with the test luminescent sample Lakowicz (2006). This requires solutions of standard and test samples to be prepared with equivalent absorbance ranges (by varying the concentrations) at the same particular excitation wavelength (Lakowicz 2006, Jobin Yvon Ltd, Fluorescence Quantum Yield Standards). The respective ratio of the integrated luminescent intensities of the two solutions yields the ratio of the quantum yield values. Since LQY for the standard sample is known, the LQY can be calculated for the test sample from Eq. 1 .

$$
Q Y_{x}=Q Y_{s t}\left(\frac{\text { slope }_{x}}{\text { slope }_{s t}}\right)\left(\frac{n_{x}^{2}}{n_{s t}^{2}}\right)
$$

where $x$ and st denote the test and standard samples, slope is the calculated slope of integrated emission against absorbance and $n$ is the refractive index of the solution.

\subsubsection{LQY results in solution}

The luminescent quantum yield values of QD-490 and QD-450 were obtained. The integrated fluorescent emission of both QDs compared with Quinine Sulphate dye is shown in Fig. 5. The gradient for each is proportional for their relative fluorescence quantum yield. Using Eq. (1), the LQY of QDs-490 and QDs-450 in toluene solution was determined to be $0.81 \pm 0.07$ and $0.51 \pm$ 0.05 respectively. Their LQY suggested that QDs-490 were a suitable candidate for processing into solid thin films to make LDS layers. The luminescent quantum yield of QDs-450 was low and resulted in an inefficient LDS layer and hence it was discontinued in the study.

Luminescent quantum yield values of Violet 570 and Yellow 083 were calculated. The integrated fluorescent emission of Violet 570 was compared with Harmane dye, and for Yellow 083 was compared with Rhodamine dye and they are shown in Figs. 6 and 7. From the slope of the integrated emission and using Eq. (1), the LQY values of Violet 570 and Yellow 083 in toluene solution were determined to be $0.99 \pm 0.08$ and $0.78 \pm 0.05$ respectively. Their LQY illustrated that they were suitable candidates for processing into solid thin films for LDS layers. The quantum yield results are presented in Table 1, along with the excitation wavelength and the

\footnotetext{
${ }^{\mathrm{f}}$ The method was tested first by comparing QY of known standard dyes Harmine, Harmane and Quinine Sulphate with literature values.
} 
comparative standard dyes used for each material.

Table 1 LQY of QDs and organic dyes in toluene solution

\begin{tabular}{cccc}
\hline \hline Luminescent Materials & Standard dye & Excitation $(\mathrm{nm})$ & QY measured Values \\
\hline QDs-490 & Quinine Sulphate & 365 & $0.81 \pm 0.07$ \\
QDs-450 & Quinine Sulphate & 365 & $0.51 \pm 0.05$ \\
Violet 570 & Harmane & 405 & $0.99 \pm 0.08$ \\
Yellow 083 & Rhodamine & 526 & $0.78 \pm 0.05$ \\
\hline
\end{tabular}

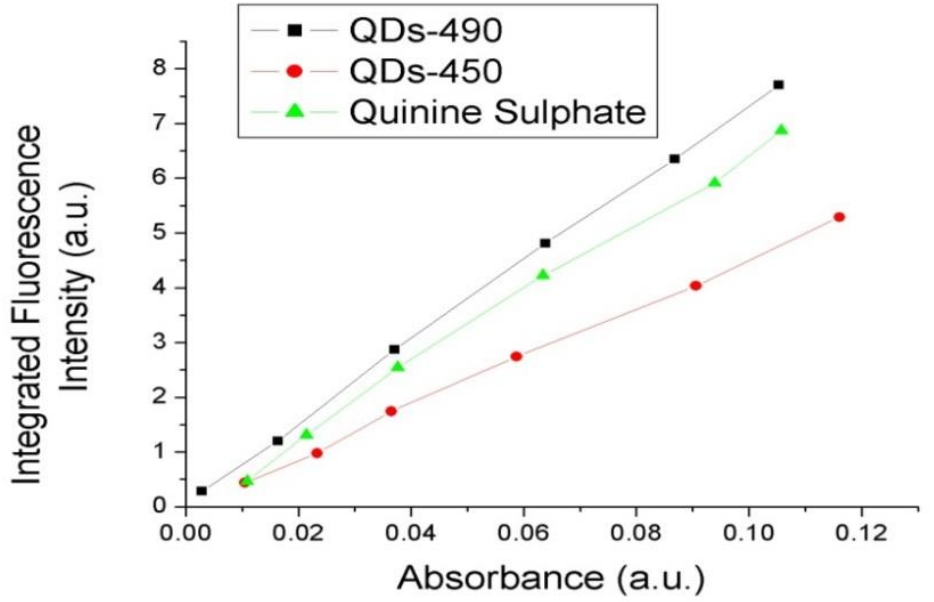

Fig. 5 Integrated fluorescence intensity for QDs-490, QDs-450 and reference Quinine Sulphate dye

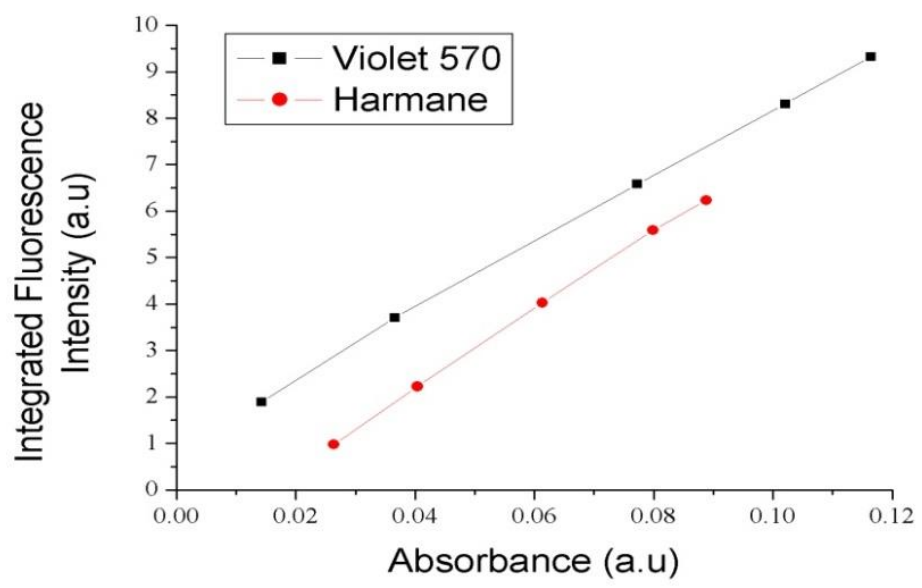

Fig. 6 Integrated fluorescence intensity for Lumogen Violet 570 and reference Harmane dye 


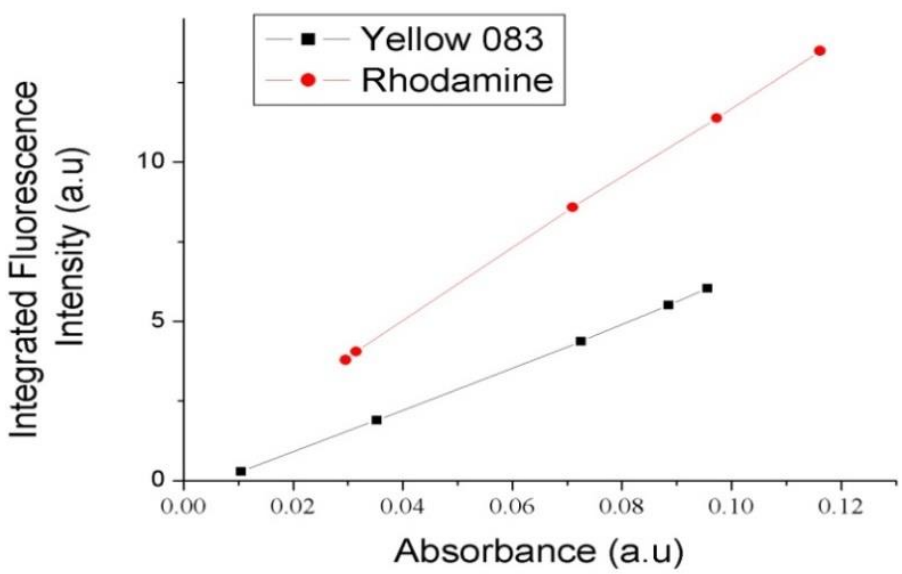

Fig. 7 Integrated fluorescence intensity for Lumogen Yellow 083 and reference Rhodamine dye

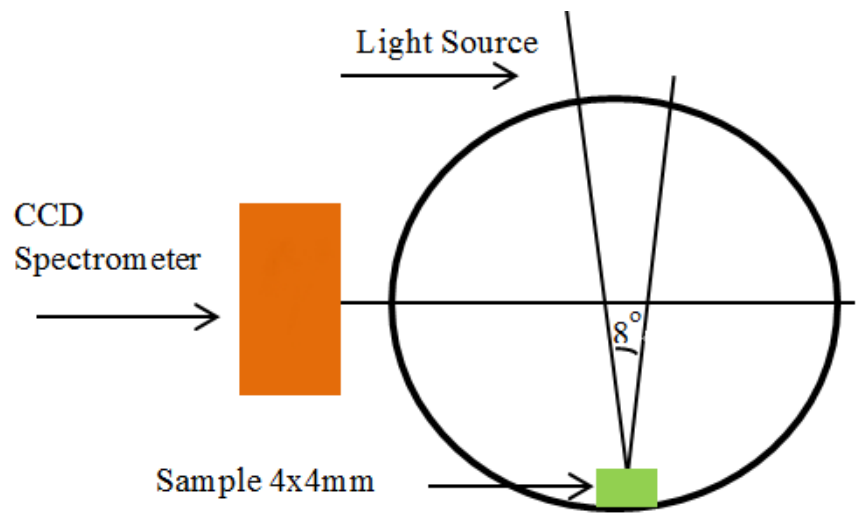

Fig. 8 Schematic diagram of integrated sphere setup for LQY measurements

\subsection{The integrating sphere technique}

Luminescent quantum yields must be quantified in solid thin films as real PV cell/LDS devices will require the incorporation of luminescent materials into solid layers. LQY may vary in solid films compared to solution because of the rigidity of the polymer host (Attia et al. 2006). Difficulties arise in using the comparative method technique for evaluating the LQY of solid thin films. The wave-guiding effects modify the angular distribution of the emission, and the test sample and the reference sample films may differ in morphology. Therefore, the LQY in thin films was determined by using the integrating sphere technique (Ahn et al. 2007, Wilson and Richards 2009 ) is illustrated in Fig. 8. The number of photons emitted is quantified relative to the total excitation photons absorbed by the sample. Filtered light from a metal-halide discharge lamp (Griven, Italy) is coupled into an integrating sphere via optical fiber. A CCD spectrometer (AVASPEC 2048-USB2, Anglia Instruments UK) is used to monitor the photon count rate exiting 
at the measurement port of the integrating sphere. All measured emission spectra are corrected for the spectral response of the detector system in totality, which was determined from comparison of a measured deuterium-halogen light source with that of the known calibrated spectrum. Photons count are taken with the sphere empty and again with the sample inserted. LQY is calculated from Eq. (2) as follows Wilson and Richards, (2009)

$$
L Q Y=\frac{\text { relative number of photons emited }}{\text { relative number of photons absorbed }}
$$

\subsubsection{Layers preparation and $L Q Y$ results}

LQY of QDs-490 is determined in PMMA (Carl Roth GmbH+Co.KG) matrix. The QDs (0.15 $\mathrm{mg} / \mathrm{ml}$ ) was added to the PMMA solution and stirred for 45 minutes resulting in homogeneous solutions. Uniform film thicknesses were created by drop casting the solutions onto glass plates. In the case of Violet 570 and Yellow 083, 1mg of each was first dissolved in $0.5 \mathrm{ml}$ toluene then added to the PMMA solution. Uniform layers of Violet 570/PMMA and Yellow 083/PMMA were achieved by drop casting the solutions onto glass plates. All layers were removed from glass after being kept for three days in fume cupboard. Their LQY, listed in Table 2, was measured with the integrating sphere technique as discussed above.

The measured LQY of QDs-490 in PMMA matrix was too low to result in a useful LDS layer. Its absorption and emission ranges though are suitable for LDS application and therefore other host materials will be sourced for testing in future studies. The Lumogen Violet 570 was found to have high luminescent quantum yield in PMMA solid film. Despite the high LQY of Lumogen Yellow 083, it is not a suitable candidate for LDS layer due to its absorption in the visible range of the solar spectrum. Yet it could be useful for thin film solar cells, such as Cadmium Telluride (CdTe) which has a poor spectral response up to $480 \mathrm{~nm}$ (Danos et al. 2012, Ross et al. 2012). It could also be used as Luminescent Solar Concentrator devices where the objective is to absorb a large fraction of the solar spectrum (van Sark et al. 2008, Rowan et al. 2008, Wilson and Richards, 2009, Kennedy et al. 2009).

\subsection{LDS layer and device fabrication}

Mono-crystalline silicon cells $(2 \times 2 \mathrm{~cm}$, Sunrydz, Germany) were used for assessing the downshifting effect of the LDS Violet 570/PMMA layer (135 microns). Two devices of each (i.e., one blank and one containing the dyes) were fabricated by depositing LDS layers on top of Si cells as shown in Fig. 9. The performances of the Si cells, both before and after the LDS encapsulation were characterized outdoors.

Table 2 LQY of QDs and organic dyes in solid PMMA film

\begin{tabular}{ccc}
\hline \hline Luminescent Materials & Excitation $(\mathrm{nm})$ & QY measured Values \\
\hline QDs-490 & 380 & $0.46 \pm 0.05$ \\
Violet 570 & 380 & $0.93 \pm 0.06$ \\
Yellow 083 & 380 & $0.71 \pm 0.05$ \\
\hline
\end{tabular}



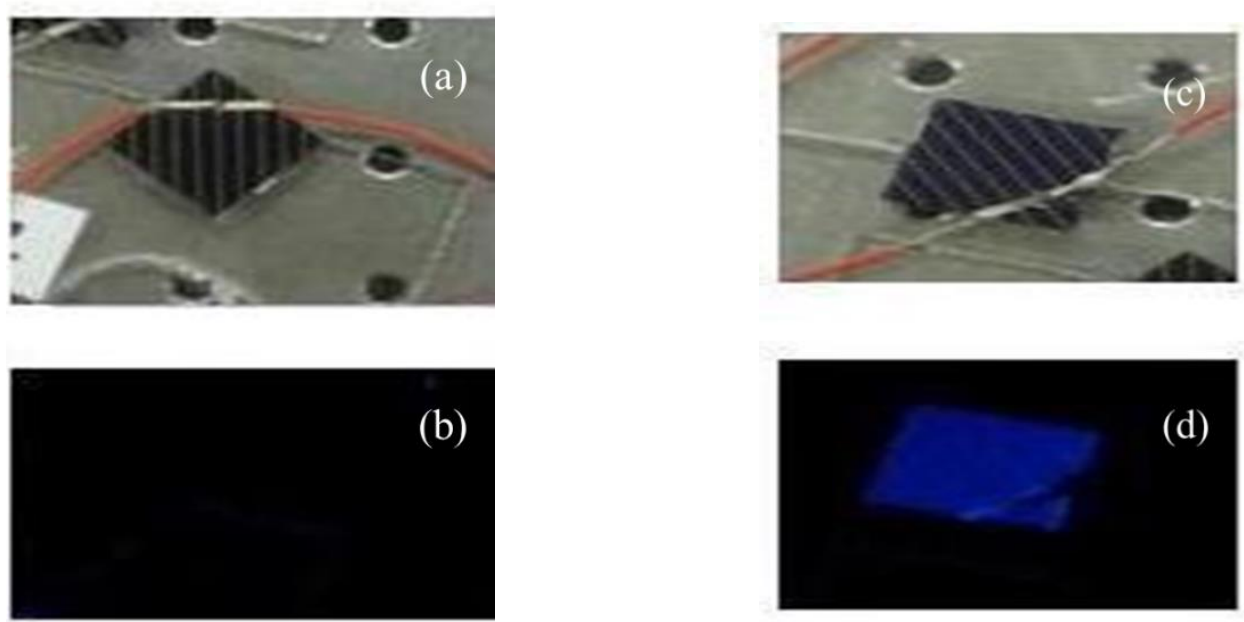

Fig. 9 Mono-crystalline Silicon cell $(2 \mathrm{~cm} \times 2 \mathrm{~cm})$ covered with PMMA layer (a) under room light, (b) under UV light, (c) mono-crystalline Silicon cell $(2 \mathrm{~cm} \times 2 \mathrm{~cm})$ covered with LDS layer of Violet/PMMA under room light and (d) under UV light

\subsection{Outdoor test}

LDS covered cells were attached to a base and mounted on the roof of Dublin Institute of Technology, Kevin St, Ireland, for outdoor characterization. The set-up consisted of two Kipp and Zonen CM-6b pyranometers aligned side by side to measure the global radiation and an EKO MS 710 spectroradiometer to record the solar spectrum from $337-1100 \mathrm{~nm}$. The data was logged using Delta T DL2e, allowing values to be recorded every minute. A horizontal platform adjacent to the pyranometers held the cells and a KEITHLEY 2400 source measurement unit allowed a voltage sweep of the cells to be performed. The four-point probe (Kelvin) method was used to determine the corresponding current, yielding the I-V curve for the solar cell. A Labview interface (Labview 2010) was used to control the settings and display the I-V and P-V curves for each cell. From these curves the fill factor $(\mathrm{FF})$, open circuit voltage $\left(\mathrm{V}_{\mathrm{oc}}\right)$ and the short circuit current $\left(\mathrm{I}_{\mathrm{sc}}\right)$ was determined. The accuracy of the voltage and current measurements is $\pm 0.0034 \%$ and $\pm 0.03 \%$ respectively. The efficiency of the cell was calculated using Eq. (3).

$$
\eta=\left(\frac{P_{\max }}{G h^{* A}}\right) x 100
$$

where, $P_{\max }$ is the maximum power calculated in $\mathrm{mW}, G h$ is the global radiation (the total short-wave radiation falling onto a horizontal surface) measured in $\mathrm{Wm}^{-2}$ and $A$ is the cell area given in $\mathrm{m}^{2}$.The efficiency calculated at the highest intensity, $705 \mathrm{Wm}^{-2}$, on the day of the measurements that is reported at 15:00 pm.

\subsection{Results and discussion}

The efficiency measured for a bare Si cell was $7.2 \%$. I-V characteristics for the blank/PMMA covered cell results in efficiency of $6.35 \%$. This decrease is due to the PMMA absorbing in the 
UV region reducing the amount of solar radiation reaching the PV cell hence, decreasing the efficiency. The Violet/PMMA covered cell gives efficiency of $8.54 \%$ when compared with blank/PMMA cell. This is a $34.5 \%$ relative increase due to the presence of Violet 570 dye down-shifting layer. I-V curves of the blank/PMMA and Violet/PMMA covered cells are shown in Fig. 10. The short circuit-current of the each device calculated as following from Eq. 4.

$$
I_{s c}(m A / W / m)^{2}=\left(\frac{I_{s c}(m A)}{G h(W / m)^{2}}\right)
$$

Considering the short circuit-current of the solar cell relative to the level of global radiation $\left(\mathrm{mA} / \mathrm{W} / \mathrm{m}^{2}\right)$, the violet/PMMA cell showed an increase of $14.4 \%$ in the short circuit-current relative to the blank/PMMA cell.

\section{Conclusions}

Quantum yield measurements techniques in solution and in thin film were developed using comparative method technique and the integrating sphere technique. It is important to use materials which have a high quantum yield for making LDS layers. The LQY obtained for QDs-490, Violet 570 and Yellow 083 in toluene solutions was found to be high $>73 \%$. This suggested that they were suitable candidates for processing into solid thin films for LDS layers. The quantum yield value for QDs-450 was found to be low and resulted in inefficient LDS layers. Luminescent down shifting layers of QDs-490, Lumogen Violet 570 and Yellow 038 organic dyes were encapsulated into PMMA matrix and characterized for their use as LDS layers to improve solar cell efficiency. LQY of $0.46 \pm 0.05$ was measured for QDs-490. This is suggested that the PMMA is not a suitable host material for the QDs-490. Alternative host materials will be investigated in future studies. LQY of $0.93 \pm 0.06$ and $0.71 \pm 0.05$ for Violet 570 and for Yellow 083 was measured respectively. An increase of $34.5 \%$ (relative) in the efficiency was calculated when Violet 570 was encapsulated within PMMA matrix. Also, an increase of $14.4 \%$ in the short circuit-current relative to the blank/PMMA cell was measured due to the presence of the Violet 570 dye. Organic dyes observed to have narrow absorption bands compared to QDs which exhibit broad absorption spectra. Overlaps between absorption and emission spectra were observed in both i.e., QDs and organic dyes, which will result in possible loss mechanisms due to re-absorption.

\section{Acknowledgements}

The authors would like to acknowledge financial support from the Higher Education Authority of Ireland.

\section{References}

Ahn, T.S., Al-Kaysi, R.O., Mueller, A.M., Wentz, K.M. and Bardeen, C.J. (2007), "Self-absorption correction for solid-state photoluminescence quantum yields obtained from integrating sphere 
measurements", Rev. Sci. Instrum., 78, 086105.

Attia, M.S., Khalil, M.M., Abdel Shafi, A.A., Attia, G.M., Failla, S., Consiglio, G., Finocchiaro, P. and Abdel Mottaleb, M.S. (2006), "Factors affecting the efficiency of excited-states interactions complexes between some visible light-emitting lanthanide ions and cyclophanes containing spirobiindanol phosphonates", Int. J. Photoenergy, 2007, 1-7.

Cheng, Z., Su, F., Pan, L., Cao, M. and Sun, Z. (2010), "CdS quantum dot-embedded silica film as luminescent down-shifting layer for crystalline si solar cells", J. Alloy. Compd., 494(1-2), L7-L10.

Danos, L., Parel, T., Markvart, T., Barrioz, V., Brooks, W.S.M. and Irvine, S.J.C. (2012), "Increased efficiencies on CdTe solar cells via luminescence down-shifting with excitation energy transfer between dyes", Sol. Energ. Mat. Sol. C., 98, 486-490.

Hovel, H.J, Hodgson, R.T. and Woodall, J.M. (1979), "The effect of fluorescent wavelength shifting on solar cell spectral response", Sol. Energ. Mat., 2(1), 19-29.

Jobin Yvon Ltd. (2013), A guide to recording fluorescence quantum yields, Available online at http://faculty.washington.edu/champak1/quantumyieldstrad.pdf. Last accessed 25/07/2013.

Kennedy, M., McCormack, S.J., Doran, J. and Norton, B. (2009), "Improving the optical efficiency and concentration of a single-plate quantum dot solar concentrator using near infra-red emitting quantum dots", Sol. Energy, 83(7), 978-981.

Klampaftis, E., Ross, D., McIntosh, K.R. and Richards, B. (2009), "Enhancing the performance of solar cell via luminescent down-shifting of the incident spectrum: a review", Sol. Energ. Mat. Sol. C., 93(8), 1182-1194.

Klampaftis, E., Ross, D., Seyrling, S., Ayodhya N., Tiwari, A.N. and Richards, B.S. (2012), "Increase in short-wavelength response of encapsulated CIGS devices by doping the encapsulation layer with luminescent material", Sol. Energ. Mat. Sol. C., 101, 62-67.

Lakowicz, J. R. (2006), Principles of Fluorescence Spectroscopy, Springer, (3rd Ed.), New York, USA.

Le Donne, A., Dilda, M., Crippa, M., Acciarri, M. and Binetti, S. (2011), "Rare earth organic complexes as down-shifters to improve si-based solar cell efficiency", Opt. Mater., 33(7), 1012-1014.

McIntosh, K.R., Lau, G., Cotsell, J.N., Hanton, K. and Batzner, D.L. (2009), "Increase in external quantum efficiency of encapsulated silicon solar cells from a luminescent down-shifting layer", Prog. Photovoltaics, 17(3), 191-197.

Ross, D., Klampaftis, E., Fritsche, J., Bauer, M. and Richards, B.S. (2012), "Increased short-circuit current density of production line CdTe mini-module through luminescent down-shifting", Sol. Energ. Mat. Sol. C., 103, 11-16.

Rothemund, R., Kreuzer, S., Umundum, T., Meinhardt, G., Fromherz, T. and Jantsch, W. (2011), "External quantum efficiency analysis of si solar cells with II-VI nanocrystal luminescent down-shifting layers", Energy Procedia, 10, 83-87.

Rowan, B.C., Wilson, L.R. and Richards, B.S. (2008), "Advance material concept for luminescent solar concentrators", IEEE J. Quantum Elect., 14(5), 1312-1322.

Strumpel, C., McCann, M., Beaucarne, G., Arkhipov, V., Slaoui, A., Svrcek, V., Del Canizo, C. and Tobias, I. (2007), "Modifying the solar spectrum to enhance silicon solar cell efficiency - an overview of available materials" Sol. Energ. Mat. Sol. C., 91(4), 238-249.

Van der Ende B.M., Aarts L. and Meijerink A. (2009), "Lanthanide ions as spectral converters for solar cells", Phys. Chem. Chem. Phys., 11, 1108-1195.

Sark, W.G.J.H.M. van, Barnham, K.W.J., Slooff, L.H., Chatten, A.J., Büchtemann, A., Andreas Meyer, A., McCormack, S.J., Koole, R., Farrell, D.J., Bose, R., Bende, E.E., Burgers, A.R., Budel, T., Quilitz, J., Kennedy, M., Toby Meyer, Donegá, C. De Mello., Meijerink, A., Vanmaekelbergh, D. (2008), "Luminescent solar concentrators - a review of recent results", Opt.Express, 16(26), 21773-21792.

Williams, A.T.R., Winfield, S.A. and Miller, J.N. (1983), "Relative fluorescence quantum yields using a computer controlled luminescence spectrometer", Analyst, 108, 1067-1071.

Wilson, L.R. and Richards, B.S. (2009), "Measurement method for photoluminescent quantum yields of fluorescent organic dyes in polymethyl methacrylate for luminescent solar concentrators", Appl. Optics, 48(2), 212-220. 